\title{
Estimation of ventricles size of human brain by Magnetic Resonance Imaging in Nepalese Population: A retrospective study
}

\author{
Sushma Singh ${ }^{* *}$, Bhoj Raj Sharma ${ }^{2}$, Urusha Prajapati ${ }^{3}$ Pujan Sharma ${ }^{4}$, \\ Manoj Bhatta ${ }^{3}$, Nawaraj Poudel ${ }^{2}$ \\ 'Lecturer/B.Sc MIT Programe Coordinator, Department of Radiology Gandaki Medical College \\ 2Lecturer, Department of Radiology Gandaki Medical College \\ ${ }^{3}$ Radiological Technologist \\ ${ }^{4}$ Associate Professor, Department of Radiology Gandaki Medical College
}

\begin{abstract}
Background and Objective: Magnetic resonance imaging (MRI) provides image acquisition of three-dimensional data and measurement in any chosen imaging plane. Objective of this study is to assess the size of ventricles of the brain of normal Nepalese people and establish the range of size of the ventricular system and compute the ventricular dimensions among different age and gender. Materials and methods: This is a cross-sectional retrospective study done at Gandaki Medical College, Pokhara. A total of 106 MRI scan data of healthy individuals were collected over a period of seven months between March to September 2019. Patients ranged between eight and eighty years of age with 58 males and 48 females. Measurements of the mean of bifrontal diameter (BFD), bihemispheric diameter (BHD), third ventricle transverse dimension (TVTD), fourth ventricle antero-posterior dimension (FVAP), fourth ventricle width (FVW), and frontal horn ratio (FHR) were done. Result: The mean of BFD, BHD, TVTD, FVAP, FVW, and FHR were found to be 3.05 $\pm 0.10 \mathrm{~cm}, 10.11 \pm 0.40 \mathrm{~cm}, 0.43 \pm 0.11 \mathrm{~cm}, 0.90 \pm 0.11 \mathrm{~cm}, 1.22 \pm 0.12 \mathrm{~cm}$, and $0.30 \pm 0.01 \mathrm{~cm}$, respectively. The mean width of fourth ventricle in males and females was observed to be $1.23 \pm 0.12 \mathrm{~cm}$ and $1.19 \pm 0.11 \mathrm{~cm}$ respectively. There was a significant correlation of TVTD, FVAP, FHR and BFD with age with Pearson correlation coefficient 0.393 (P value $<0.01$ ), 0.259 ( $\mathrm{P}$ value $<0.01$ ), 0.34 ( $\mathrm{P}$ value $<0.01$ ), and 0.219 (P value $<0.05$ ) respectively. However, BHD and FVW have no correlation with age. Conclusion: Third Ventricle Traverse Dimension, FVP, FVW and FHR show almost similar or slight difference in measurement according to gender. However, BFD shows larger difference in measurement according to gender. Similarly there is no such significant difference according to age in measurement of BFD, BHD, FVAP, FVW and FHR, while TVTD measurement shows slight increased measurement according to age.
\end{abstract}

Keywords: Brain, Brain ventricles, Magnetic resonance imaging, Ventricular size

\section{Correspondence}

Sushma Singh

Department of Radiology, Gandaki Medical College

Email: forssbrt@gmail.com

Submitted: April 25, 2020

Accepted: May 17, 2020

To cite: Singh S, Sharma BR, Prajapati U, Sharma P, Bhatta M, Poudel N. Estimation of ventricles size of human brain by Magnetic Resonance Imaging in Nepalese Population: A retrospective study. JGMC Nepal. $2020 ; 13(1): 45-50$. DOI: $10.3126 /$ igmcn.v13i1.28542

\section{INTRODUCTION}

MRI is a non-invasive medical test that helps to diagnose and treat medical conditions. MRI scanners use strong magnetic fields, magnetic field gradients, and radio waves to generate images of the organs in the body. The brain ventricular system is a cavity filled with cerebrospinal fluid, the fluid which protects the brain and spinal cord from trauma, supplies nutrients to nervous system tissue, and removes waste products from cerebral metabolism. Understanding the normal and abnormal anatomy of the ventricular system of the brain is helpful for the clinician, neurosurgeon, and radiologist in day-to-day practices. The abnormal anatomy of the lateral ventricle may be great academic interest regarding cerebrospinal fluid circulation and also important for surgical intervention. ${ }^{1}$ Morphometric analysis of cerebral 
ventricular system is important for evaluating changes due to growth, ageing, intrinsic, ad extrinsic pathology. ${ }^{2}$ The advantages given by the modern imaging methods and minimally invasive technique motivated many of the researchers to study the anatomy of the ventricular system and measure the distances in individuals. ${ }^{3}$

The cerebral ventricles are of a relatively fixed shape and size and in the absence of diseases, do not vary significantly, and systematic study is desirable to establish this point. ${ }^{4}$ to understand these changes the knowledge of normal morphometry and size of normal ventricular system of brain is important..$^{5}$ The advantages given by the modern imaging methods and minimally invasive technique motivated many of the researchers to study the anatomy of ventricular system and measure the distances in individuals. ${ }^{3}$ Morphometric analysis of brain structure such as volume, shape, and size of ventricular system especially lateral ventricle, recently has become the main focus of interest in studies of some neuropsychiatric diseases like Alzheimer's. ${ }^{6}$ Further, the knowledge of measurement of the ventricular system of the brain by MRI is of use in the diagnosis of some diseases like hydrocephalus, schizophrenia and surgical intervention like endoscopic neurosurgery. ${ }^{7}$

Very few studies have been done to study the ventricular size using MRI technique as well as there is limited study in the Nepalese population. In this study, an attempt has been made to establish the ranges of normal values for the measurement of the ventricular system by use of MRI. The objective of the study was to establish the size range of ventricular system in normal brain MRI and compute the FHR of healthy Nepalese people. After the study, we will be able to compare the ventricular size and FHR of the Nepalese population with other Asians and other ethnicities.

\section{MATERIALS AND METHODS}

The Retrospective cross-sectional study was conducted at Department of Radio diagnosis and imaging, Gandaki Medical College Teaching Hospital \& Research Centre (GMCTHRC), Pokhara metropolitan city, Kaski with the approval of the Ethical committee of Institutional Review Board of GMC.

A total of 106 healthy individuals patient MRI scan were collected from MRI workstation which was performed between March to September 2019, aged between eight to 80 years of which 58 were males and 48 were females. Inclusion criteria for this study were MRI scan of Brain and patients with no known pathologies or abnormalities of brain. Exclusion criteria for the study were evidence of abnormality i.e. space occupying lesions, cerebral hemorrhage, brain tumor, head injuries, previous intracranial surgeries, metal implants, image with significant noise, and uncooperative patients. Only Nepalese patients were included, any foreigner or nonNepalese patients were also excluded from the study.

The total number of patients was divided into four groups, all patients less than 20 years of age were kept in the first group, age between 20 to 39 years were kept in the second group, 40 to 59 years in the third group, and age of 60 and above were kept in the fourth group. MRI was conducted using Seimens Magnetom Essenza, 1.5 tesla machine and measurement of the ventricles were done in and T2 axial spin-echo (CSF differentiation is best seen in $\mathrm{T} 2$ images) sequence having slice thickness of $5 \mathrm{~mm}$, Distance factor $=40 \%$ of slice thickness, repetition time (TR) 3600 (milliseconds) and Echo time (TE) $106 \mathrm{~ms}$, Bandwidth= 190.0, Field of View $($ FOV $)=194 X 230$, FOV phase $=84.4 \%$, Concantenations $=1$. The patient was placed in MRI table and centering was done in correlation with brain coil. All the measurements were taken under the standard protocol made by the radiological society with the help of an inbuilt measuring tool from viewing option of MRI console computer. Data were collected in Performa and was kept in Microsoft excel 2016.

Measurement of the lateral ventricle was done at the level of the bilateral caudate nucleus, third ventricle below the level of the interventricular foramen of Monro and fourth ventricle at the level of pontomedullary junction.

\section{Measurement of BFD: (Figure 1)}

The maximum bifrontal diameter is the transverse distance defined by a line connecting two anterior corners of the frontal horns 'a' and 'b'.

\section{Measurement of bihemispheric diameter: (Figure 2)}

The brain width or bihemispheric diameter is the distance measured along the line of bifrontal diameter to the brain edge ' $c$ ' and ' $d$ '.

\section{Calculation of FHR:}

Frontal horn ratio is the greatest distance between the tips of the frontal horn divided by the first transverse diameter of the brain along the same level. Frontal horn ratio $=\mathrm{BFD}$ divided by $\mathrm{BHD}$ 


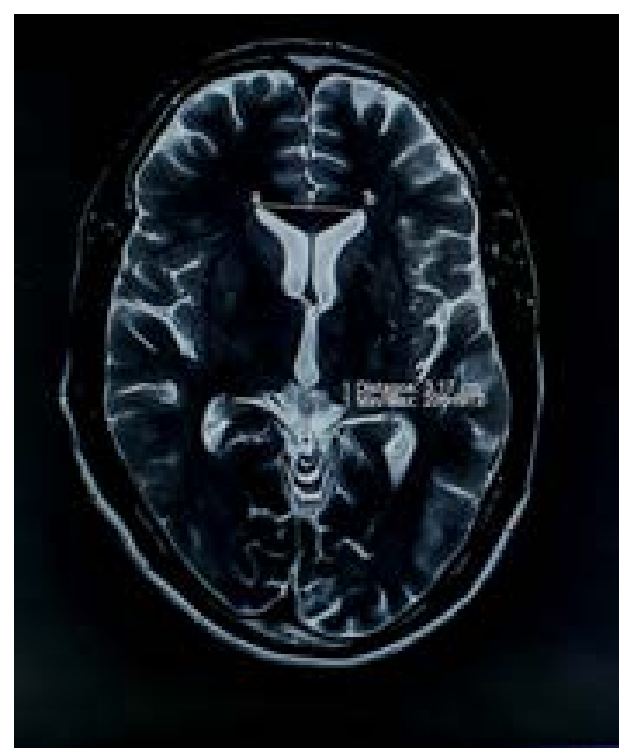

Fig. 1: MRI Scan of brain showing TVD of frontal horn (BFD) (a-b)

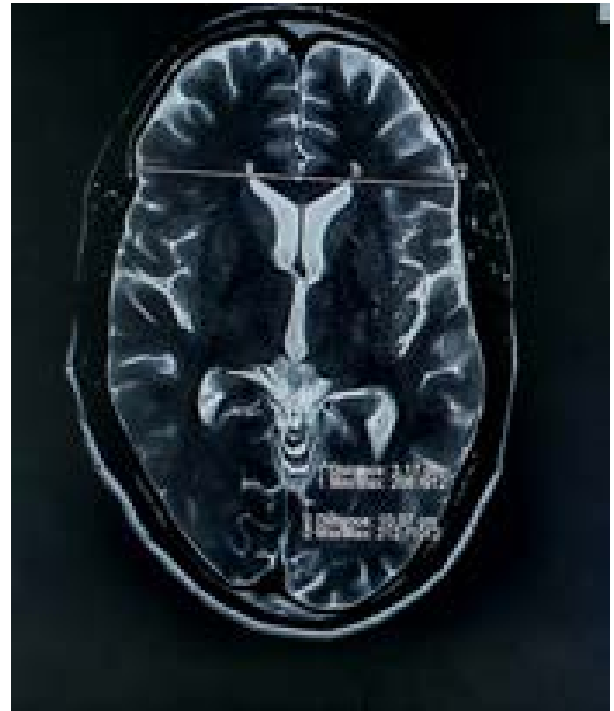

Fig. 2: MRI Scan of brain showing BHD (c-d) along the BFD (a-b)

Measurement of third ventricle transverse dimension: (Figure 3)

The transverse dimension of third ventricle is the greatest distance between lateral margins of the third ventricle from ' $e$ ' to ' $f$ '.

Measurement of anterior-posterior dimension and width of the fourth ventricle: (Figure 4)

The greatest anterior- posterior dimension of fourth ventricle is the distance from anterior aspect of vermis to the posterior aspect of pons, ' $a$ ' line connecting 'I' and ' $\mathrm{j}$ ' and the width is the maximum transverse distance along the coronal plane connecting ' $g$ ' and ' $h$ '.

\section{Statistical analysis:}

Statistical analysis was carried out with the help of SPSS version 25 . The mean, standard deviation, and correlation between size of ventricles of brain among different age groups and gender were expressed in tables and figures. Pearson correlation test was conducted to compare two variables.

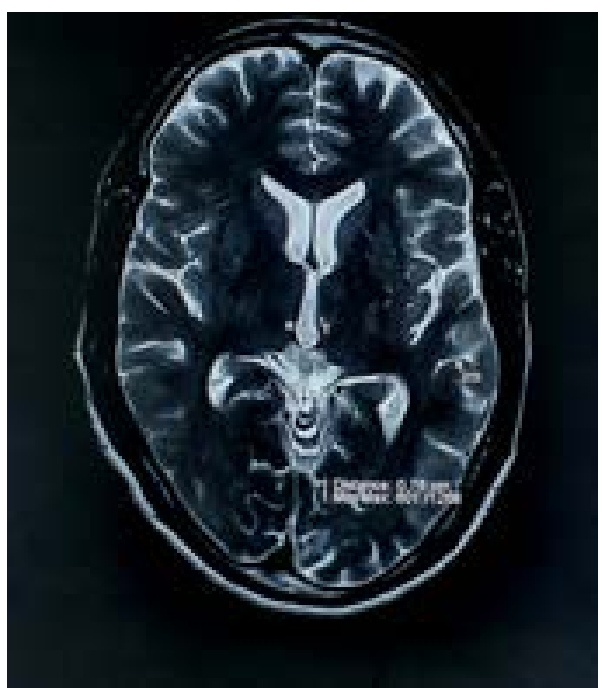

Fig. 3: MRI Scan of brain showing greatest diameter of third ventricle (e-f)

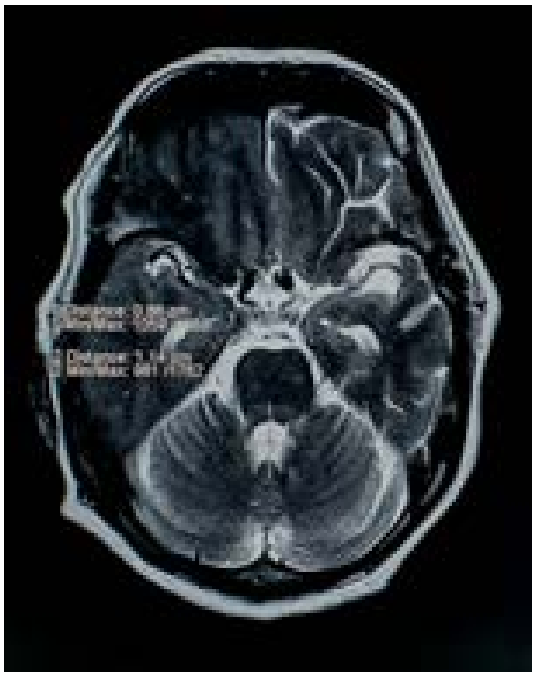

Fig. 4: MRI Scan of brain showing greatest ventricle diameter $(i-j)$ and greatest transverse diameter $(g-h)$ along coronal plane of axial section.

\section{RESULT}

The data was collected from 106 normal individuals, 58 (54.7\%) males and 48 (45.3\%) females with age range from eight years old to 81 years old. Data were presented as mean and standard deviation of all variables. Detailed results are shown in the table 1 
Table 1: Sample distribution on the basis of age group

\begin{tabular}{ccc}
\hline Age group & Frequency & Percent \\
less than 20 & 16 & 15.1 \\
$20-39$ & 35 & 33.0 \\
$40-59$ & 26 & 24.5 \\
60 and above & 29 & 27.4 \\
Total & 106 & 100.0 \\
\hline
\end{tabular}

Table 2: Comparison of different parameters of ventricle size of Human brain according to gender

\begin{tabular}{|c|c|c|c|c|c|c|c|}
\hline Sex & & BFD & BHD & TVTD & FVAP & FVW & FHR \\
\hline \multirow{2}{*}{ Male } & $\begin{array}{l}\text { Mean } \\
( \pm S D)\end{array}$ & $\begin{array}{c}3.123 \pm 0 . \\
204\end{array}$ & $\begin{array}{c}10.24 \mid \pm 0 \\
398\end{array}$ & $\begin{array}{c}0.443 \pm 0 \\
114\end{array}$ & $\begin{array}{c}0.907 \pm 0 \\
119\end{array}$ & $\begin{array}{c}1.236 \pm 0 \\
127\end{array}$ & $\begin{array}{c}0.305 \pm 0 \\
017\end{array}$ \\
\hline & $\mathrm{N}$ & 58 & 58 & 58 & 58 & 58 & 58 \\
\hline \multirow{2}{*}{ Female } & $\begin{array}{l}\text { Mean } \\
( \pm S D)\end{array}$ & $\begin{array}{c}2.966 \pm 0 \\
156\end{array}$ & $\begin{array}{c}9.963 \pm 0 \\
349\end{array}$ & $\begin{array}{c}0.420 \pm 0 \\
108\end{array}$ & $\begin{array}{c}0.895 \pm 0 \\
100\end{array}$ & $\begin{array}{c}1.199 \pm 0 . \\
113\end{array}$ & $\begin{array}{c}0.297 \pm 0 \\
013\end{array}$ \\
\hline & $\mathrm{N}$ & 48 & 48 & 48 & 48 & 48 & 48 \\
\hline \multirow{2}{*}{ Total } & $\begin{array}{l}\text { Mean } \\
( \pm S D)\end{array}$ & $\begin{array}{c}3.052 \pm 0 \\
199\end{array}$ & $\begin{array}{c}10.115 \pm 0 . \\
400\end{array}$ & $\begin{array}{c}0.433 \pm 0 \\
111\end{array}$ & $\begin{array}{c}0.902 \pm 0 \\
111\end{array}$ & $\begin{array}{c}1.220 \pm 0 \\
121\end{array}$ & $\begin{array}{c}0.301 \pm 0 \\
016\end{array}$ \\
\hline & $\mathrm{N}$ & 106 & 106 & 106 & 106 & 106 & 106 \\
\hline
\end{tabular}

Legends: Bifrontal diameter (BFD), bihemispheric diameter (BHD), third ventricle transverse diameter (TVTD), fourth ventricle antero-posterior diameter (FVAP), fourth ventricle width (FVW) and frontal horn ratio (FHR)

\section{Values are measured in centimetre $(\mathrm{cm})$}

Table 2 explains the mean and standard deviation of the BFD, BHD, TVTD, FVAP, FVW, and FHR based on gender.

Mean BFD was observed to be larger in male (3.12 \pm 0.20$)$ $\mathrm{cm}$ than compared to $(2.96 \pm 0.15) \mathrm{cm}$ in female. Similarly, mean BHD was observed to be $(10.24 \pm 0.39) \mathrm{cm}$ in male patients and $(9.96 \pm 0.34) \mathrm{cm}$ in female patients. Mean of TVTD was $(0.44 \pm 0.11) \mathrm{cm}$ for male and $(0.42 \pm 0.10)$ $\mathrm{cm}$ for female. The mean of FVAP of male and female was observed to be $(0.90 \pm 0.11) \mathrm{cm}$ and $(0.89 \pm 0.10)$ $\mathrm{cm}$ respectively. Similarly, the mean of FVW of male and female was observed to be $(1.23 \pm 0.12) \mathrm{cm}$ and $(1.19 \pm$ 0.11 ) $\mathrm{cm}$ respectively.

The mean FHR was found to be $(0.30 \pm 0.01) \mathrm{cm}$ in male and $(0.29 \pm 0.01) \mathrm{cm}$ in female.
Table 3: Comparison of different parameters of ventricle size of human brain according to age group

\begin{tabular}{cccccccc}
\hline Age Group & BFD & BHD & TVTD & FVAP & FVW & FHR \\
$\begin{array}{c}\text { less } \\
\text { than } \\
\mathbf{2 0}\end{array}$ & Mean & $3.058 \pm 0$. & $10.253 \pm 0$. & $0.391 \pm 0$. & $0.847 \pm 0$. & $1.222 \pm 0$. & $0.298 \pm 0$. \\
& $\mathrm{N}$ & 111 & 348 & 066 & 096 & 106 & 011 \\
& & 16 & 16 & 16 & 16 & 16 & 16 \\
& Mean & $2.993 \pm 0$. & $10.100 \pm 0$. & $0.400 \pm 0$. & $0.893 \pm 0$. & $1.215 \pm 0$. & $0.296 \pm 0$. \\
$\mathbf{2 0 - 3 9}$ & $( \pm \mathrm{SD})$ & 183 & 414 & 064 & 076 & 108 & 013 \\
& $\mathrm{~N}$ & 35 & 35 & 35 & 35 & 35 & 35 \\
& $\mathrm{Mean}$ & $3.016 \pm 0$. & $10.071 \pm 0$. & $0.428 \pm 0$. & $0.903 \pm 0$. & $1.182 \pm 0$. & $0.299 \pm 0$. \\
$\mathbf{0 - 5 9}$ & $( \pm \mathrm{SD})$ & 211 & 420 & 084 & 138 & 134 & 013 \\
& $\mathrm{~N}$ & 26 & 26 & 26 & 26 & 26 & 26 \\
$\mathbf{6 0}$ & $\mathrm{Mean}$ & $3.153 \pm 0$. & $10.096 \pm 0$. & $0.500 \pm 0$. & $0.941 \pm 0$. & $1.257 \pm 0$. & $0.312 \pm 0$. \\
and & $( \pm \mathrm{SD})$ & 213 & 395 & 161 & 117 & 126 & 019 \\
above & $\mathrm{N}$ & 29 & 29 & 29 & 29 & 29 & 29 \\
& $\mathrm{Mean}$ & $3.052 \pm 0$. & $10.115 \pm 0$. & $0.433 \pm 0$. & $0.902 \pm 0$. & $1.220 \pm 0$. & $0.301 \pm 0$. \\
Total & $( \pm \mathrm{SD})$ & 199 & 400 & 111 & 111 & 121 & 016 \\
& $\mathrm{~N}$ & 106 & 106 & 106 & 106 & 106 & 106 \\
\hline
\end{tabular}

Legends: bifrontal diameter (BFD), bihemispheric diameter (BHD), third ventricle transverse diameter (TVTD), fourth ventricle antero-posterior diameter (FVAP), fourth ventricle width (FVW) and frontal horn ratio (FHR)

\section{Values are measured in $\mathrm{cm}$.}

Table 3 explains the mean of BFD, BHD, TVTD, FVAP, FVW, and FHR was found to be $3.05 \pm 0.10 \mathrm{~cm}, 10.11 \pm 0.40 \mathrm{~cm}$, $0.43 \pm 0.11 \mathrm{~cm}, 0.90 \pm 0.11 \mathrm{~cm}, 1.22 \pm 0.12 \mathrm{~cm}$ and $0.30 \pm$ $0.01 \mathrm{~cm}$ respectively.

As seen in the table, the measured BFD was almost equal in all age groups with slight variation and also similar results were observed in case of BHD. It can be summarized that the mean values in case of TVTD were slightly increasing according to increase in age. The FVAP and FVW were observed to be high at sixth decades of life.

Table 4: Correlation of different parameters of ventricle size of human brain with age

\begin{tabular}{|c|c|c|c|c|c|c|c|}
\hline & & BFD & BHD & TVTD & FVAP & FVW & FHR \\
\hline \multirow{2}{*}{$\begin{array}{l}\text { Over } \\
\text { all } \\
\text { Age }\end{array}$} & $\begin{array}{l}\text { Pearson } \\
\text { Correlation }\end{array}$ & $0.219^{*}$ & $-0.102^{*}$ & $0.393^{* *}$ & $0.259^{* *}$ & $0.122 *$ & $0.340^{* *}$ \\
\hline & $P$ value & 0.024 & 0.300 & 0.000 & 0.007 & 0.212 & 0.000 \\
\hline \multicolumn{8}{|c|}{$\begin{array}{l}\text { *. Correlation is significant at the } 0.05 \text { level } \\
\text { **. Correlation is significant at the } 0.01 \text { level }\end{array}$} \\
\hline
\end{tabular}

Legends: bifrontal diameter (BFD), bihemispheric diameter (BHD), third ventricle transverse diameter (TVTD), fourth ventricle antero-posterior diameter 
(FVAP), fourth ventricle width (FVW) and frontal horn ratio (FHR)

Table 4 explains that there was significant correlation of TVTD, FVAP, and FHR with overall age at level of significance 0.01 . There was significant correlation of BFD with age at level of 0.05. BHD and FVW have no significant correlation with age. $(\mathrm{P}$ value $>0.05)$

\section{DISCUSSION}

The objectives of this study were to establish range of size of ventricular system in normal brain MRI and compute the ventricular dimensions among different age and gender. The adult human brain has size of around $1130 \mathrm{~cm}^{3}$ in women and $1260 \mathrm{~cm}^{3}$ in men. Male brains are about $10 \%$ larger than female brain in volume and weighs 11 to $12 \%$ more than female. ${ }^{8}$

According to Hahn and Rimet et al. ${ }^{9}$ the cerebroventricular index (FHR) seems to be a reliable indicator of ventricular size and emphasizes the study of normal ventricles. Another study done by Cala et al. ${ }^{10}$ found ventriculo-internal cranial ratio (FHR) of $(0.31 \pm 0.08)$ in female and $(0.33 \pm 0.06)$ in male i.e. genders were not statistically significant, however our study, found the FHR at level of tips of frontal horn varied from minimum value of 0.29 to 0.31 from age of 8 to 80 years averaging $(0.30 \pm 0.16)$. The male result was found to be $0.30 \pm 0.01 \mathrm{~cm}$, which was almost equal while female result was found to be $0.29 \pm 0.01 \mathrm{~cm}$ that was quite less than their study. Our study showed slightly different result than that of D'Souza and Natekar et al..$^{11}$ in terms of third ventricle transverse diameter (TVTD) who studied on morphometry of ventricular system for the large sample size and found the TVTD in male and female were $(0.45$ $\pm 0.29 \mathrm{~cm})$ and $(0.39 \pm 0.17 \mathrm{~cm})$ respectively, but in our current study, male width was found to be $(0.44 \pm 0.11 \mathrm{~cm})$ comparable to their finding, whereas female width was $0.42 \pm 0.10 \mathrm{~cm}$ which was higher than they observed. Singh et al. ${ }^{5}$ found that the TVTD was slightly lower in male $(0.34$ $\pm 0.10 \mathrm{~cm})$ than in female $(0.33 \pm 0.09 \mathrm{~cm})$, which is higher than our study, $0.44 \pm 0.11 \mathrm{~cm}$ in male and $0.42 \pm 0.10 \mathrm{~cm}$ in female. Satapara et al. ${ }^{7}$ suggests that TVTD increases with increase in age which is statistically significant, their study shows the value for age group less than 20 to be $(0.34 \pm$ $0.05)$ and for the maximum of age group 60 and above $(0.92 \pm 0.42)$ giving a mean of $(0.52 \pm 0.24)$.Similarly, our study shows that TVTD increases slightly with age. Our study shows that there is statistically significant differences (P value $<0.05)$, for age group less than 20 years be $(0.39 \pm$ $0.06)$ and for the age group 60 and above $(0.50 \pm 0.16)$ giving a mean of $(0.43 \pm 0.11)$.
Study by D'Souza et al. ${ }^{11}$ found the FVAP to be $0.11 \pm 0.002$ $\mathrm{cm}$ in male and $0.11 \pm 0.002 \mathrm{~cm}$ in female. In our study, mean FVAP in male and female was higher than the study done by D'Souza and Natekar et al. ${ }^{11}$. Fourth ventricle in male and female was similar to the study done by D'Souza and Natekar et al. ${ }^{11}$ Also, it was concluded that FVW was observed to be larger than its antero- posterior diameter in both male and female as found in their study.

Duffner et al. ${ }^{3}$ measured the FVW with a mean of $1.25 \pm$ $0.17 \mathrm{~cm}$ which was comparable with present calculation of width with overall mean of $1.22 \pm 0.12 \mathrm{~cm}$.

\section{CONCLUSION}

We can conclude that TVTD, FVP, FVW and FHR shows almost similar or slight difference in measurement according to gender. However, BFD shows larger difference in measurement according to gender. Similarly there is no such significant difference according to age in measurement of BFD, BHD, FVAP, FVW and FHR. While TVTD measurement shows slight increased measurement according to age, there changes are also commented by other researcher with small sample and large sample size. However, in order to say exact range of ventricles size in Nepalese population we recommend measurement with large sample size as well for comparison in Nepalese population. There may be personal variation in measurement as it's done manually.

\section{Limitations of the study}

Because of the time limitation and experimental difficulties for age variation of ventricle size data were taken from different subjects with different ages instead from the single subject at different age structural changes of human brain with age is expected to be normal.

\section{Recommendations}

Further studies for measurement of size of ventricles with larger sample size are recommended for more accuracy in results. Volumetric measurement is recommended as it provides more information than linear measurement. Further studies are recommended to be done with more body characteristics for more and meaningful information.

\section{Acknowledgement:}

We would like to specially thank all the MRI and CT Technologist and Radiologist who helped us to conduct this research.

\section{Conflict of Interest:}

None declared 


\section{REFERENCES}

1. Srjit D, Shipe P. Anatomical study of anomalous posterior horn of lateral ventricle of brain and its clinical significance. Bratisl Lek Listy. 2007;108(9):422-4. PMID: 18225483.

2. Rathod PU, Shembekar S. Morphometric study of posterior horn of lateral ventricle and its correlation with age and side: A CTstudy. Int J Anat Res. 2018;6(1.2):4901-05. DOI: 10.16965/ijar.2017.504

3. Duffner F, Schiffbaur H, Glemser D, Skalei M, Freudenstein D. Anatomy of the cerebral ventricular system for the endoscopic neurosurgery: a magnetic resonace study. Acta Neurochir(Wien). 2003;145(5):359-68. DOI: 10.1007/S00701-0030021-6

4. Evans WA. An encephalographic ratio for estimating the size of the cerebral ventricles: further experience with serial observations. Am J of Dis Child. 1942;1;64(5):820-30. DOI: 10.1001/ archpedi.1942.02010110052006

5. Singh BR, Gajbe U, Agrawal A, Reddy YA, Bhartiya S. Ventricles of brain: a morphometric study by computerized tomography. Int. J Med Res Health Sci. 2014;3(2):381-7. DOI: 10.5958/j.23195886.3.3.079

6. Ashtari MA, Zito JL, Gold BI, Lieberman JA, Borenstein MT, Herman PG. Computerized volume measurement of brain structure. Investigative Radiology. 1990 Jul;25 (7):798-805. DOI: 10.1097/00004424199007000-00009

7. Satapara VK, Patel MM, Rathava JK, Trivedi PN, Kukadiya UC, Gohil DV et al. Morphometry of width of third ventricle of brain by luminal cast plastination \& MRI. Int J of Adv. Res. 2014;2(6):837-42.

8. Zaidi ZF. Gender differences in human brain: A Review. The open anatomy journals. 201014;2:3755. DOI: $10.2174 / 1877609401002010037$

9. Hahn FJ, Rim K. Frontal ventricular dimensions on normal computed tomography. AJR Am J Roentgenol. 1976;126(3):593-6. DOI: 10.2214/ ajr.126.3.593

10. Cala LA, Thickbroom GW, Black JL, Collins DW, Mastaglia FL. Brain density and cerebrospinal fluid space size: CT of normal volunteers. Am J Neuroradiol. 1981;2(1):41-7. PMID: 6784549.
11. D'Souza-e-Dias-Medora C, Natekar-Prashant E. Morphometric study of the ventricular system of brain by computerised tomography. J Anat Soc India 2007;56(1):19-24. 